\title{
Janus Kinase-2 Mutation Associated Portal Vein Thrombosis Complicating Liver Cirrhosis and Hepatocellular Carcinoma
}

\author{
Hatem Rabie ${ }^{1}$, Warda Othman ${ }^{2}$, Dalia M Elsabaawy ${ }^{3 *}$, Eman E. Elshemy ${ }^{4}$, \\ Neamat Abdelmageed ${ }^{4}$, Fatma A Khalaf ${ }^{5}$, Hanan M Bedair ${ }^{1}$
}

\begin{abstract}
Background: Portal vein thrombosis (PVT) might be a catastrophic event complicating liver cirrhosis and hepatocellular carcinoma (HCC). Aim: role of $J A K 2 R S V 617 F$ mutation as a risk factor for PVT development in liver cirrhosis and HCC. Methods: A case control study conducted on 100 PVT patients (76 HCC and 24 liver cirrhosis) additionally, 100 healthy individuals used as a control group. PVT was diagnosed incidentally by Doppler ultrasound during routine follow-up HCC screening. Prothrombin G20210A mutation, MTHFR mutation, Factor V Leiden mutation (VFL), antithrombin III (ATIII), protein C, S, and antiphospholipid antibodies, along with JAK2 RS V617F mutation by real-time polymerase chain reaction all were analyzed. Results: Patients with PVT were significantly older $(\mathrm{p}<0.001)$, thrombocytopenic $(\mathrm{p}<0.001)$, with high alkaline phosphatase $(\mathrm{p}<0.001)$. JAK2 RS V617F mutation was found in 28/100 (28\%) in idiopathic PVT complicating liver cirrhosis and hepatocellular carcinoma. Cases with positive $J A K 2$ rs $V 617 F$ mutation were significantly accompanied by protein S deficiency (P 0.03), LA absence (p 0.06), and high frequency of ascites (P 0.03). While, the MTHFR heterozygous mutation (p0.001), ATIII (P 0.02), and VFL (P 0.01) were more frequent with negative $J A K 2$ rs $V 617 F$ mutation. The comparison between demographic data and thrombophilic parameters in PVT cases revealed that no significant differences were recorded except for male gender, Diabetes Mellitus, splenomegaly significantly increased among HCC cases $(\mathrm{p}<0.05)$. Conclusions: JAK2 rs V617F mutation must be considered in any case of PVT with liver cirrhosis and hepatocellular carcinoma without identified thrombophilic risk factors, with potential considerations of evolving myeloproliferative disorders. New diagnostic and therapeutic implications are still awaited.
\end{abstract}

Keywords: JAK2 RS V617F mutation- portal vein thrombosis- liver cirrhosis- hepatocellular carcinoma

Asian Pac J Cancer Prev, 22 (1), 267-275

\section{Introduction}

Portal vein thrombosis (PVT) is defined as a partial or complete obstruction of the portal vein by a clot resulting in impeded flow (Margini and Berzigotti, 2016), its prevalence ranges between $0.6 \%$ and $26 \%$ in cirrhotic and in about $35 \%$ in the setting of cirrhosis with hepatocellular carcinoma (HCC) (Tsochatzis et al., 2010; Chawla and Bodh, 2015). PVT may present with abdominal pain, portal hypertension, ascites, gastrointestinal bleeding, or mesenteric ischemia. Liver cirrhosis is among the most common acquired risk factors for portal vein thrombosis (PVT) and it is responsible for approximately $20 \%$ of all cases. Although PVT is most commonly seen in the setting of cirrhosis, many patients develop PVT in the absence of cirrhosis due to a combination of other prothrombotic factors (Fimognari and Violi, 2008). Also, HCC, acute pancreatitis, and intra-abdominal infection, systemic factors, including hypercoagulable states and sepsis, also pose an increased risk. The myeloproliferative neoplasms (MPNs) are associated with systemic prothrombotic states and are less frequently identified as the cause of PVT (Rao and Grosel, 2018).

PVT and Budd-Chiari syndrome (BCS) are relatively rare disorders; however, can be fatal if the underlying etiological factors are not diagnosed and treated. They have similar symptoms (splenomegaly, ascites, pain, and melena, etc.) and etiological factors such as factor $V$ Leiden (VFL) mutation, prothrombin gene (G20210A mutation), protein $\mathrm{C}$ and protein $\mathrm{S}$ deficiency, and MPNs (Karaköse et al., 2015).

Janus kinase 2 (JAK2) is a non-receptor tyrosine

${ }^{1}$ Departments of Clinical Pathology, National Liver Institute, Menoufia University, Egypt. ${ }^{2}$ Hepatology, National Liver Institute-Menoufia University, Egypt. ${ }^{3}$ Lecturer of Clinical Pharmacy, National Liver Institute, Menoufia University, Egypt. ${ }^{4}$ Hepatogastroentrology and Infectious Diseases, Faculty of Medicine for girls, AL-Azhar University, Egypt. ${ }^{5}$ Department of Biochemistry, National Liver Institute, Menoufia University, Menoufia, Egypt. *For Correspondence: 
kinase, which, upon ligand binding to specific cytokine receptors, is phosphorylated and activated, leading to regulation of gene expression involved in cell proliferation and survival. The acquired $J A K 2$ gene mutation on chromosome $9(J A K 2 V 617 F)$ is a mutation in $\mathrm{G}$ to $\mathrm{T}$ somatic mutation at nucleotide 1849 in exon 14, resulting in the substitution of valine to phenylalanine at codon 617, which triggers constitutive activation of downstream signaling and uncontrolled cell growth (Palumbo et al., 2019).

The acquired $J A K 2$ gene mutation on chromosome $9(J A K 2 \mathrm{V6} 17 \mathrm{~F})$ is associated with polycythemia vera (PV) and other related MPNs (Tefferi and Gilliland 2005). The reported prevalence of the $J A K 2$ mutation has ranged from $65 \%-97 \%$ in polycythemia vera (PV) patients from Europe and North America, 23\%-57\% in patients with essential thrombocythemia (ET), and 35\%-57\% in primary myelofibrosis (PMF) patients (Yonal et al., 2012). The JAK2 rs V617F mutation has been implicated as an independent risk factor for portal and mesenteric vein thrombosis (Colaizzo, et al., 2007; Pan and Callahan, 2016).

A meta-analysis by Dentali et al. assessed the frequency of the JAK2 RS V617F is not only splanchnic vein thrombosis but also other thromboembolism including deep vein thrombosis and cerebral vein thrombosis. The $J A K 2$ rs $V 617 F$ mutation was noted to be more strongly associated with splanchnic vein thrombosis and it has been hypothesized that the $J A K 2$ mutation may affect the blood flow through the splanchnic venous bed (Dentali, et al., 2009).

The JAK2 rs $V 617 F$ mutation is a noninvasive molecular marker for occult MPNs and can be used for the diagnosis of latent MPNs presenting with thrombotic events, and the patients with idiopathic PVT or BCS showed that $20 \%$ had latent MPNs. In addition to this $J A K 2$ mutation, prothrombotic events were observed in a significant number of patients with splanchnic vein thrombosis. JAK2 gene analysis should be included in the research panel for BCS and PVT patients without cirrhosis (Karaköse et al., 2015).

The patients with venous thrombosis at other sites, the $J A K 2$ rs $V 617 F$ mutation was no more common than in the general population, and the frequency of the $J A K 2$ rs $V 617 F$ mutation was more strongly associated with PVT even in absence of other risk factors. The mechanisms underlying these findings have not been fully elucidated, therefore, the current study was designed.

\section{Aim of the study}

This study aimed to detect the role of JAK2 rs V617F mutation in patients with chronic liver disease (cirrhosis and hepatocellular carcinoma) and clarify its value as a new risk factor for the development of portal vein thrombosis compared to other conventional thrombophilic factors.

\section{Materials and Methods}

The current study was carried out on 100 patients with chronic liver disease (76 of them were HCC and
24 were with liver cirrhosis), who were attending the Hepatology and gastroenterology department at the National Liver institute-Menoufia University during the period from September 2018 to October 2019. In cirrhotic and HCC patients, PVT often is diagnosed incidentally by ultrasound during routine follow-up screening for HCC. Additionally, 100 apparently healthy individuals were enrolled in the study as a control group

All patients were subjected to complete history taking stressing on transient risk factors for venous thromboembolism (trauma, malignancy, surgery, pregnancy, oral contraceptive use, hormonal replacement therapy. A thorough clinical examination was done along with color Doppler Ultrasound for the evaluation of hepatic, inferior vena cava, and portal veins.

The research was approved by Ethical committee of National liver institute Menoufia University. An informed written consent was a prerequisite before enrollment in this study.

The inclusion criteria were: Age 18 years or older, all patients had liver cirrhosis or HCC confirmed with PVT proved by clinical, laboratory investigations and color Doppler Ultrasound examination.

The exclusion criteria: Any cause of PVT due to causes other than liver cirrhosis or HCC (such as Familial thrombophilia, thrombosis after surgical interference, Budd Chiari syndrome, or infections)

Peripheral blood samples were collected from all patients and controls and divided into two ethylene diamine tetra-acetic acid dipotassium salt (K2-EDTA) vacutainer tubes for $\mathrm{CBC}$ and RT-PCR and one citrate vacutainer tube for coagulation profile.

The following routine laboratory Investigations were done include Complete blood picture (CBC) using Sysmex automatic cell counter (Japan). PT, INR, and APTT using a fibrin timer analyzer. Liver and kidney function tests (ALT, AST, Albumin, total bilirubin, GGT, and ALP) were done by using the Integra 800 Auto analyzer (Roche-Germany).

Thrombophilia screening tests: prothrombin G20210A mutation, MTHFR mutation, Factor $V$ Leiden mutation, serum level of antithrombin III, protein $\mathrm{C}$, protein $\mathrm{S}$, and antiphospholipid antibodies (lupus anticoagulant and anticardiolipin), the screening tests results were obtained from patient files.

Detection of JAK2 rs $V 617 F$ mutation was done by Rotor gene $\mathrm{Q}$ real-time polymerase chain reaction (QIAGEN, GmbH-Germany). DNA extraction: Genomic DNA isolation from PBMCs was done using Gene JET Whole Blood Genomic DNA Purification Mini Kit (Thermo Scientific) according to Manufacturers' instructions. The extracted DNA were tested to DNA purity, and finally stored at $-80^{\circ} \mathrm{C}$ until subjected for real time PCR (Qiagen, 2016).

Detection of JAK2 mutation was done by JAK2 Muta Screen Kit (catalog no. 673022, ipsogen, Germany) for the detection of the $J A K 2$ rs $V 617 F / G 1849 T$ mutation in genomic DNA. Two Taq Man probes are used, one is a perfect match to allele 1 sequence (e.g., mutant allele), and the other is a perfect match to allele 2 sequence (e.g., the wild-type allele). Each probe at its 5' end is labeled with a different fluorescent dye (FAM or VIC), the reporter, 
Janus kinase-2 Mutation Portal Vein Thrombosis IN Hepatocellular Carcinoma

and at the 3' end contains a non-fluorescent quencher. During the extension phase of PCR, the perfectly matched probe is cleaved by the 5 ' $\rightarrow 3^{\prime}$ ' exonuclease activity of Taq DNA polymerase, separating the reporter dye from the quencher and thus releasing detectable fluorescence. The probe that not perfectly matched will be displaced and no reporter dye will be released. The fluorescence signal (VIC or FAM) generated is collected at the end of the PCR (end-point) and immediately indicates the presence of the targeted sequence(s) in the sample (wild-type allele, mutated allele or both). Generation of fluorescence signal only with FAM dye indicate homozygous mutation while generation of fluorescence signal from FAM and VIC indicate heterozygous mutation (Qiagen, 2016).

\section{Statistical Methods}

Results were statistically analyzed using the statistical package of social sciences (SPSS 22.0, IBM/SPSS Inc., and Chicago, IL). Normally distributed continuous variables were expressed as mean and standard deviation (mean $\pm \mathrm{SD}$ ) while not normally distributed expressed as the median and interquartile range (IQR). Categorical data were expressed as frequency and percentage. For comparing continuous variables, ANOVA test was used when normality and homogeneity assumptions were met, instead, their non-parametric equivalent Kruskal-Wallis or Mann-Whitney tests were applied. The Chi-square test was used to compare categorical variables or alternatively, Fisher's exact test was used when Chi-square assumptions were violated. The statistical significance was set at P-value $<0.05$.

\section{Results}

Patients with PVT were found to be significantly older $(\mathrm{p}<0.001)$, thrombocytopenic $(\mathrm{p}<0.001)$, with higher levels of liver enzymes especially alkaline phosphatase $(p<0.001)$. Comparison between PVT cases and controls regards demographic and routine laboratory variables revealed a statistically significant increase in the WBCs

Table 1. Comparison between PVT Cases and Controls Regards Routine Laboratory Variables

\begin{tabular}{|c|c|c|c|c|}
\hline & Parameters & PVT Cases $(\mathrm{N}=100)$ & Healthy controls $(\mathrm{N}=100)$ & p-value \\
\hline \multirow[t]{2}{*}{ Age (years) } & Mean \pm SD & $58.3 \pm 6.3$ & $49.3 \pm 3.6$ & \\
\hline & Min-max & $33-68$ & $35-61$ & 0.32 \\
\hline \multirow[t]{2}{*}{$\mathrm{HB}(\mathrm{g} / \mathrm{dl})$} & Median (IQR) & $11.0(3.0)$ & $13.0(1.0)$ & $<0.001$ \\
\hline & Min-max & $7-16$ & $11-17$ & $<0.001$ \\
\hline \multirow[t]{2}{*}{ WBCs $\left(\times 10^{3}\right)$} & Median (IQR) & $9.0(4)$ & $7.0(2)$ & $<0.001$ \\
\hline & Min-max & $3-19$ & $4-10$ & $<0.001$ \\
\hline \multirow[t]{2}{*}{ Platelets $\left(x 10^{3}\right)$} & Median (IQR) & $169.0(160)$ & 276.5 (149) & $<0.001$ \\
\hline & Min-max & $50-519$ & $182-441$ & $<0.001$ \\
\hline \multirow[t]{2}{*}{ ALT (IU/L) } & Median (IQR) & $33.0(39)$ & $18.5(12)$ & $<0.001$ \\
\hline & Min-max & $6-735$ & $10-29$ & $<0.001$ \\
\hline \multirow[t]{2}{*}{ AST (IU/L) } & Median (IQR) & $52.0(79)$ & $19.0(8)$ & $<0.001$ \\
\hline & Min-max & $8-2248$ & $10-29$ & $<0.001$ \\
\hline \multirow[t]{2}{*}{ GGT (IU/L) } & Median (IQR) & $66.0(102)$ & $19.0(5)$ & $<0.001$ \\
\hline & Min-max & $12-534$ & $10-32$ & $<0.001$ \\
\hline \multirow[t]{2}{*}{ ALK ph (IU/L) } & Median (IQR) & $132.0(77)$ & $59.0(23)$ & $<0.001$ \\
\hline & Min-max & $44-990$ & $31-99$ & $0.24 *$ \\
\hline \multirow[t]{2}{*}{ Albumin (g/dl) } & Median (IQR) & $3.0(1.6)$ & $4.0(0.3)$ & $<0.001$ \\
\hline & Min-max & $1-5$ & $4-4.9$ & \\
\hline \multirow[t]{2}{*}{ T. Bilirubin (mg/dl) } & Median (IQR) & $2.0(7.0)$ & $0.4(0.2)$ & $<0.001$ \\
\hline & Min-max & $0.3-25$ & $0.2-1$ & \\
\hline \multirow[t]{2}{*}{ INR } & Median (IQR) & $1.4(0.5)$ & $1.0(0.03)$ & $<0.001$ \\
\hline & Min-max & $1-2.3$ & $0.9-1.1$ & \\
\hline \multirow[t]{2}{*}{ Urea (mg/dl) } & Median (IQR) & $64.0(112)$ & $32.0(6.0)$ & $<0.001$ \\
\hline & Min-max & $20.0-214.0$ & $23.0-42.0$ & \\
\hline \multirow[t]{2}{*}{ Creatinine (mg/dl) } & Median (IQR) & $1.1(0.7)$ & $0.7(0.1)$ & $<0.001$ \\
\hline & Min-max & $0.6-4.6$ & $0.6-0.99$ & \\
\hline \multirow[t]{2}{*}{$\operatorname{AFP}(\mathrm{ng} / \mathrm{ml})$} & Median (IQR) & $72.2(6647.3)$ & $2.35(1)$ & $<0.001$ \\
\hline & Min-max & $0.73-150218.0$ & $1.5-6.2$ & \\
\hline \multirow[t]{2}{*}{ MTHFR } & Wild & $58(58)$ & $66(66)$ & $0.24^{*}$ \\
\hline & Heterozygous & $42(42)$ & $34(34)$ & \\
\hline
\end{tabular}

LA, lupus anticoagulant; ACL, anticardiolipin; DAAS, direct acting antiviral drugs, FVL, factor V Leiden; MTHFR, methyl-tetrahydrofolate reductase; $\mathrm{P}>0.05$ is non-significant; $\mathrm{p}<0.05$ : is significant; *Chi square test (x2) is used. 
Table 2. The Distribution of JAK2 Mutation among Other Risk Factors of PVT

\begin{tabular}{|c|c|c|}
\hline Causes & Parameters & PVT patients $(\mathrm{N}=100)$ No $(\%)$ \\
\hline I. Idiopathic: & Cases with JAK2 mutation only & $28(28)$ \\
\hline II. Secondary causes & Cases with another factor mutation or risk factors for thrombophilia & $72(72)$ \\
\hline \multirow[t]{24}{*}{ Secondary causes } & Protein $\mathrm{C}$ deficiency & $28(28)$ \\
\hline & Protein S deficiency & $10(10)$ \\
\hline & ATIII deficiency & $52(52)$ \\
\hline & MTHFR mutation: & \\
\hline & Wild & $58(58)$ \\
\hline & Heterozygous & $42(42)$ \\
\hline & FVL mutation: & \\
\hline & Wild & $88(88)$ \\
\hline & Mutant & $12(12)$ \\
\hline & Prothrombin G20210A mutation & \\
\hline & Wild & $96(96)$ \\
\hline & Mutant & $4(4)$ \\
\hline & Antiphospholipid syndrome & \\
\hline & $\operatorname{ACL}(\operatorname{Ig} M)$ & $8(8)$ \\
\hline & LA & $10(10)$ \\
\hline & Tumor number in $\mathrm{HCC}$ cases $(\mathrm{N}=76)$ & \\
\hline & Single & $32(42)$ \\
\hline & Multiple & $44(57.9)$ \\
\hline & Liver cirrhosis & $24(24)$ \\
\hline & Ascites & $70(70)$ \\
\hline & History of DAADs & $44(44)$ \\
\hline & Diabetes mellitus & $46(46)$ \\
\hline & Smoking & $17(17)$ \\
\hline & Male gender & $84(84)$ \\
\hline
\end{tabular}

count, liver enzymes, bilirubin, INR, creatinine, urea, and AFP levels in PVT patients compared to healthy controls ( $p<0.001$ ). In contrast, the levels of $\mathrm{HB}$, platelet count, serum albumin were significantly decreased in patients with PVT $(p<0.001)$. No significant differences were reported regards age and $M T H F R$ mutation $(\mathrm{p}<0.24)$
(Table 1).

The distribution of $\mathrm{J} A K 2$ mutation among idiopathic PVT cases with either HCC or liver cirrhosis was about 28/100 (28\%), while secondary causes (cases with other thrombophilic risk factors) were found to be $72 / 100$ $(72 \%)$ (Table 2$)$. The comparison between demographic

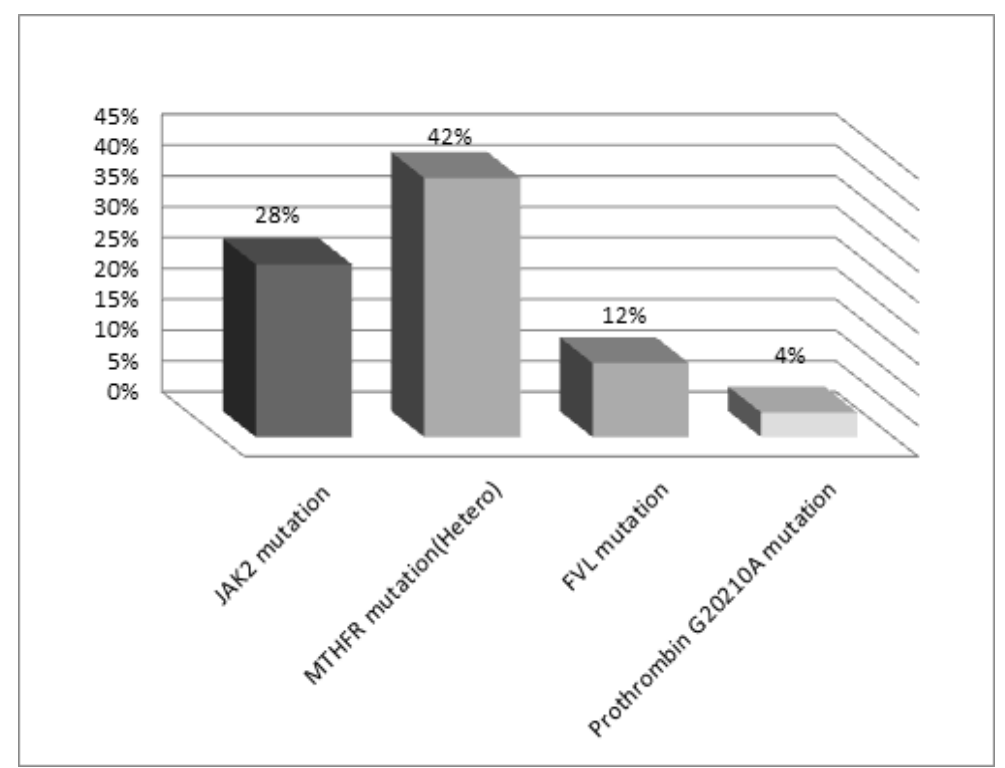

Figure 1. Genetic Mutation Frequencies of Thrombophilic Factors among PVT Patients 
Janus kinase-2 Mutation Portal Vein Thrombosis IN Hepatocellular Carcinoma Table 3. Comparison between Demographic Data and Thrombophilic Parameters in PVT Cases

\begin{tabular}{|c|c|c|c|c|}
\hline Parameters & & $\mathrm{HCC}(\mathrm{N}=76) \mathrm{N}(\%)$ & Cirrhosis $(\mathrm{N}=24) \mathrm{No}(\%)$ & P- Value \\
\hline \multirow[t]{2}{*}{ Age (years) } & Median (IQR) & $60.0(8)$ & $33.0(13)$ & 0.32 \\
\hline & Min-max & $43-65$ & $68-35$ & \\
\hline \multirow[t]{2}{*}{ Gender } & Male & $68(89.5)$ & $16(66)$ & $0.02 *$ \\
\hline & Female & $8(10.5)$ & $8(33.3)$ & \\
\hline JAK2 RS V617F & Positive & $22(28.9)$ & $6(25)$ & 0.7 \\
\hline \multirow[t]{2}{*}{ Organomegaly } & Hepatomegaly & $30(39.5)$ & $8(33.3)$ & 0.58 \\
\hline & Splenomegaly & $66(86.8)$ & $16(66.7)$ & $0.03^{*}$ \\
\hline Smoking & Positive & $13(17.1)$ & $4(16.7)$ & $0.94 *$ \\
\hline Diabetes mellitus & Positive & $28(36.8)$ & $18(75)$ & 0.001 \\
\hline Protein $\mathrm{C}$ & Deficiency & $20(26.3)$ & $8(33.3)$ & 0.5 \\
\hline Protein S & Deficiency & $8(10.5)$ & $2(8.3)$ & $1.00^{*}$ \\
\hline ATIII & Deficiency & $40(52.6)$ & $12(50)$ & 0.82 \\
\hline FVL & Mutation & $10(13.2)$ & $2(8.3)$ & $0.72 *$ \\
\hline G20210A & Mutation & $4(5.3)$ & $0(0)$ & $0.57 *$ \\
\hline MTHFR & Heterozygous & $36(47.4)$ & $6(25)$ & 0.05 \\
\hline LA & Positive & $8(10.5)$ & $2(8.3)$ & $1.00^{*}$ \\
\hline ACL (IgM) & Positive & $6(7.9)$ & $2(8.3)$ & $1.00^{*}$ \\
\hline \multirow[t]{2}{*}{ Ascites } & Absent & $18(23.7)$ & $12(50)$ & 0.01 \\
\hline & Present & $58(76.3)$ & $12(50)$ & \\
\hline History of DAAS & Receiving & $42(55.3)$ & $10(41.7)$ & $0.27^{*}$ \\
\hline \multirow[t]{3}{*}{ Child score } & A & $19(26.3)$ & $5(33.3)$ & 0.11 \\
\hline & B & $22(28.9)$ & $9(16.7)$ & \\
\hline & $\mathrm{C}$ & $35(46.1)$ & $10(50)$ & \\
\hline
\end{tabular}

LA, lupus anticoagulant; ACL, anticardiolipin; DAAS, direct acting antiviral drugs; FVL, factor V Leiden; MTHFR,: methyl-tetrahydrofolate reductase; $\mathrm{P}>0.05$ is non-significant; $\mathrm{p}<0.05$ : is significant; ${ }^{*}$ Chi square test $(\mathrm{x} 2)$ is used.

data and thrombophilic parameters in PVT cases revealed that no significant differences were recorded except for male gender, DM, splenomegaly which is increased significantly increased among HCC cases ( $p$ vaules $=0.02,0.001,0.03$ respectively) (Table 3 ).

Comparison between age and routine laboratory parameters in PVT cases shows a significant decrease in the levels of $\mathrm{HB}, \mathrm{WBCs}$, and platelet $(\mathrm{p}<0.001)$. While AST and AFP serum levels were significantly decreased in HCC cases with PVT compared to cirrhotic cases with PVT $(\mathrm{p}<0.001)$. No significant differences were reported regarding the other parameters $(\mathrm{P}>0.05)$ (Table 4$)$.

The cases with positive $J A K 2$ rs $V 617 F$ mutations were found to be significantly accompanied by protein

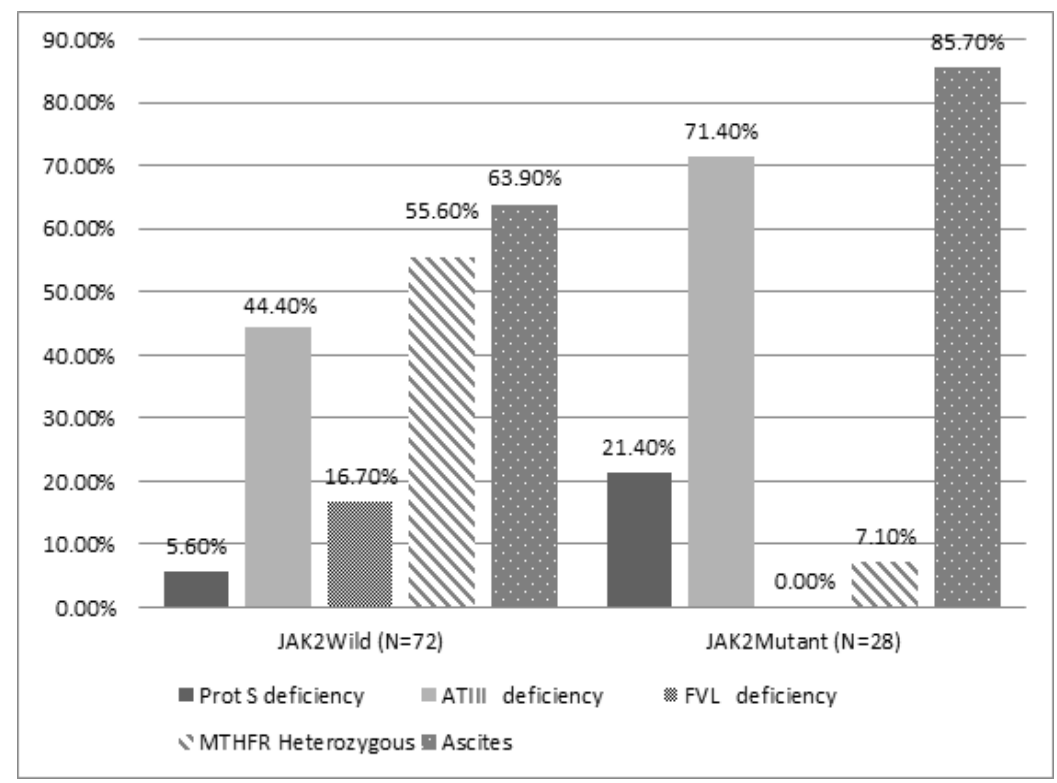

Figure 2. Significant Thrombophilic Factors Associated with JAK2 Mutation 
Table 4. Comparison between Age and Routine Laboratory Parameters in PVT Cases

\begin{tabular}{|c|c|c|c|c|}
\hline Parameters & & $\mathrm{HCC}(\mathrm{N}=76)$ & Cirrhosis $(\mathrm{N}=24)$ & p-value \\
\hline \multirow[t]{2}{*}{$\mathrm{HB}(\mathrm{g} / \mathrm{dl})$} & Median (IQR) & $11.0(3)$ & $9.5(2)$ & 0.02 \\
\hline & Min-max & $7-16$ & $8-14$ & \\
\hline \multirow[t]{2}{*}{ WBCs $\left(x 10^{3}\right)$} & Median (IQR) & $8.50(4)$ & $10.0(3)$ & 0.02 \\
\hline & Min-max & $3-19$ & $7-16$ & \\
\hline \multirow[t]{2}{*}{ Platelets $\left(\mathrm{x} 10^{3}\right)$} & Median (IQR) & $149.0(123)$ & $265.0(143)$ & 0.002 \\
\hline & Min-max & $57-519$ & $50-354$ & \\
\hline \multirow[t]{2}{*}{ Neutrophils \% } & Median (IQR) & $77.50(19)$ & $79.50(13)$ & 0.13 \\
\hline & Min-max & $44-91$ & $66-88$ & \\
\hline \multirow[t]{2}{*}{ lymphocytes\% } & Median (IQR) & $14.00(16)$ & $11.50(14)$ & 0.18 \\
\hline & Min-max & $4-38$ & $4-28$ & \\
\hline \multirow[t]{2}{*}{$\operatorname{ALT}(\mathrm{IU} / \mathrm{L})$} & Median (IQR) & $35.0(42)$ & $30.0(32)$ & 0.5 \\
\hline & Min-max & $6-735$ & $12-69$ & \\
\hline \multirow[t]{2}{*}{$\operatorname{AST}(\mathrm{IU} / \mathrm{L})$} & Median (IQR) & $52.0(99)$ & $40.0(48)$ & 0.04 \\
\hline & Min-max & $8-2248$ & $11-126$ & \\
\hline \multirow[t]{2}{*}{ GGT (IU/dl) } & Median (IQR) & $62.50(96)$ & $61.50(113)$ & 0.75 \\
\hline & Min-max & $15-534$ & $12-456$ & \\
\hline \multirow[t]{2}{*}{ ALK ph (IU/dl) } & Median (IQR) & $129.0(79)$ & $132.0(114)$ & 0.96 \\
\hline & Min-max & $44-990$ & $61-537$ & \\
\hline \multirow[t]{2}{*}{ Albumin (g/dl) } & Median (IQR) & $2.60(1.50)$ & $2.70(1.32)$ & 0.72 \\
\hline & Min-max & $1.00-4.90$ & $1.20-3.60$ & \\
\hline \multirow[t]{2}{*}{ T. bilirubin $(\mathrm{mg} / \mathrm{dl})$} & Median (IQR) & $2.0(6.20)$ & $2.19(13.26)$ & 0.58 \\
\hline & Min-max & $0.40-23.80$ & $0.30-25.20$ & \\
\hline \multirow[t]{2}{*}{ INR } & Median (IQR) & $1.46(0.50)$ & $1.51(0.79)$ & 0.47 \\
\hline & Min-max & $1.00-2.33$ & $1.06-2.23$ & \\
\hline \multirow[t]{2}{*}{ Urea (mg/dl) } & Median (IQR) & $50.5(112.80)$ & $76.50(88.75)$ & 0.93 \\
\hline & Min-max & $22.0-214.0$ & $20.0-151.0$ & \\
\hline \multirow[t]{2}{*}{ Creatinine (mg/dl) } & Median (IQR) & $1.10(0.072)$ & $1.135(0.32)$ & 0.82 \\
\hline & Min-max & $0.60-4.60$ & $0.60-3.19$ & \\
\hline \multirow[t]{2}{*}{$\operatorname{AFP}(n g / d l)$} & Median (IQR) & $339.5(14543.4)$ & $2.09(21.84)$ & $<0.001$ \\
\hline & Min-max & $1.10-150,218$ & $0.73-294.20$ & \\
\hline
\end{tabular}

$\mathrm{P}>0.05$ is non-significant; $\mathrm{p}<0.05$ : is significant; Kruskal Wallis (U) test is used

S deficiency (P 0.03), LA absence (p 0.06), and high frequency of ascites $(\mathrm{P}=0.03)$. While, the MTHFR heterozygous mutation $(\mathrm{P}=0.001)$, ATIII $(\mathrm{P}=0.02)$ and $\operatorname{VFL}(\mathrm{P}=0.01)$ were more frequent with negative $J A K 2$ rs $V 617 F$ mutation. No significant differences were reported regarding the other thrombophilic risk factors, demographic and clinical data with $J A K 2$ mutation in patients with portal vein thrombosis $(\mathrm{P}>0.05)$ (Table 5).

Non-significant differences were found between the CBC parameters, liver and kidney function tests, or serum AFP levels on comparing negative and positive JAK2 rs $V 617 F$ mutation cases $(\mathrm{P}>0.05)$ (Table 6).

\section{Discussion}

Patients with advanced liver cirrhosis and HCC represent a poor sector of patients gathering a dismal group of ailments that might end by PVT. The risk of PVT was said to increase in patients with liver cirrhosis by more than 7-fold increase above the general population (Ogren et al., 2006). Reports also had mentioned that the occurrence of only $1 \%$ of PVT in compensated cirrhosis which rises to $8 \%-25 \%$ in candidates for liver transplantation and $40 \%$ in the setting of HCC (Ponziani et al., 2012; Intagliata et al., 2018). These facts were evident in this study concluded when comparing cases with PVT and healthy control cases with a highly significant difference regarding complete blood picture, liver and kidney function tests and AFP

Dealing with liver cirrhosis and HCC as a direct initiative of PVT is a fact but still in need of explanation. Chawla and Bodh, (2015) and Basit et al., (2015) found that the incidence of PVT among cirrhotic was $11.2 \%-16.6 \%, 20 \%-44 \%$ respectively, and in about $35 \%$ in HCC combined with cirrhosis. However, inherited or acquired thrombophilia were also seen in up to $20 \%$ of individuals with PVT with cirrhosis and HCC. Accordingly, liver cirrhosis either with or without HCC is not per se a cause of PVT and there might be a role for hidden thrombophilic disorders to be unveiled.

$J A K 2$ rs $V 617 F$ mutation as a potential risk factor of PVT was studied added to other thrombophilic disorders in a cohort with liver cirrhosis and HCC. In the current 
Janus kinase-2 Mutation Portal Vein Thrombosis IN Hepatocellular Carcinoma Table 5. Comparison between Negative and Positive JAK2 RS V617F Mutation Cases as Regards Demographic and Clinical Data

\begin{tabular}{|c|c|c|c|c|}
\hline Parameter & & $\begin{array}{c}\text { Wild JAK2 }(\mathrm{No}=72) \text { No } \\
(\%)\end{array}$ & $\begin{array}{c}\text { Mutant JAK2 }(\mathrm{No}=28) \\
\text { No }(\%)\end{array}$ & P- Value \\
\hline \multirow[t]{2}{*}{ Age (years) } & Median (IQR) & $42.50(19)$ & $60.0(4)$ & \\
\hline & Min-max & $33-68$ & $50-65$ & 0.64 \\
\hline \multirow[t]{2}{*}{ Sex } & Male & $60(83.3)$ & $24(85.75)$ & 1 \\
\hline & Female & $12(16.7)$ & $4(14.3)$ & Fisher's exact \\
\hline \multirow[t]{2}{*}{ Organomegaly } & Hepatomegaly & $30(1.7)$ & $8(28.6)$ & $0.22\left(\mathrm{x}^{2}\right)$ \\
\hline & Splenomegaly & $58(80.6)$ & $24(85.7)$ & $0.54\left(\mathrm{x}^{2}\right)$ \\
\hline Smoking & Positive & $9(12.5)$ & $8(28.6)$ & $0.13\left(\mathrm{x}^{2}\right)$ \\
\hline Hypertension & Present & $21(27.6)$ & $7(25)$ & $0.27\left(\mathrm{x}^{2}\right)$ \\
\hline $\mathrm{DM}$ & Present & $32(44.4)$ & $14(50)$ & $0.6\left(\mathrm{x}^{2}\right)$ \\
\hline Protein C & deficiency & $18(25.0)$ & $10(35.7)$ & $0.28\left(\mathrm{x}^{2}\right)$ \\
\hline Protein S & deficiency & $4(5.6)$ & $6(21.4)$ & $0.03 *$ Fisher's exact \\
\hline ATIII & deficiency & $32(44.4)$ & $20(71.4)$ & $0.02\left(\mathrm{x}^{2}\right)$ \\
\hline FVL & Mutation & $12(16.7)$ & $0(0)$ & $0.01\left(\mathrm{x}^{2}\right)$ \\
\hline G20210A & Mutation & $2(2.8)$ & $2(7.1)$ & $0.57\left(\mathrm{x}^{2}\right)$ \\
\hline MTHFR & Heterozygous & $40(55.6)$ & $2(7.1)$ & $<0.001\left(\mathrm{x}^{2}\right)$ \\
\hline LA & Positive & $10(13.9)$ & $0(0)$ & $0.06 *$ Fisher's exact \\
\hline $\mathrm{ACL}$ & Positive & $6(8.3)$ & $2(7.1)$ & $1.00 *$ Fisher's exact \\
\hline \multirow[t]{2}{*}{ Ascites } & Absent & $26(36.1)$ & $4(14.3)$ & \\
\hline & Present & $46(63.9)$ & $24(85.7)$ & $0.03\left(\mathrm{x}^{2}\right)$ \\
\hline History of DAAS & Positive & $40(55.6)$ & $12(42.9)$ & 0.29 Fisher's exact \\
\hline Tumor number: & Single & $24(44.4)$ & $8(36.45)$ & $0.51\left(\mathrm{x}^{2}\right)$ \\
\hline HCC cases $(n=76)$ & Multiple & $30(55.6)$ & $14(63.6)$ & \\
\hline Tumor size: & $<5 \mathrm{~cm}$ & $30(55.6)$ & $16(72.7)$ & $0.16\left(\mathrm{x}^{2}\right)$ \\
\hline HCC cases $(n=76)$ & $=>5 \mathrm{~cm}$ & $24(44.4)$ & $6(27.3)$ & \\
\hline \multirow[t]{3}{*}{ Child score: } & A & $17(23.6)$ & $7(25)$ & \\
\hline & $\mathrm{B}$ & $23(31.9)$ & $8(28.6)$ & $0.12\left(\mathrm{x}^{2}\right)$ \\
\hline & $\mathrm{C}$ & $32(44.5)$ & $13(46.4)$ & \\
\hline
\end{tabular}

LA, lupus anticoagulant; ACL, anticardiolipin; DAAS, direct acting antiviral drugs; FVL, factor V Leiden; MTHFR, methyl-tetrahydrofolate reductase; $\mathrm{P}>0.05$ is non-significant; $\mathrm{p}<0.05$ : is significant

study, JAK2 mutation was found to be prevalent in 28/100 $(28 \%)$ of cases with idiopathic PVT and secondary causes (cases with another factor mutation or acquired risk factors for thrombophilia) were about $72 / 100(72 \%)$ of while cases. A finding which might imply a significant role of $J A K 2$ mutation in the development of PVT in patients with chronic liver disease even without overt myeloproliferative neoplasms (MPNs).

The association between MPNs with JAK2 rs V617F mutation had been suggested to be linked to splanchnic vein thrombosis (Dentali et al., 2009). Therefore, a case of latent MPNs might be present irrespective of the normal thrombophilic or coagulation risk factors in hepatic patients.

Likewise, it might be the scenario in cases with PVT complicating liver cirrhosis and HCC with latent MPNs veiled by the devastating symptoms and signs of advanced chronic liver diseases. Hence, liver cell failure mortality in many instances might be attributed to evolving MPNs to death. Suppositions possibly would rationalize a lot of unexplained deteriorated chronic liver disease cases.
In agreement with our finding Amitrano et al., (2004) detected that inherited thrombophilic disorders in more than two-thirds of cirrhotic patients with PVT and the prothrombin gene $20210 \mathrm{~A}$ mutation were found to be associated with a more than a five-fold increased risk of developing PVT. Additionally, Amitrano et al., (2000) found that factor VLeiden mutation and MTHFR-C677T mutation are more frequently detected in cirrhotic patients with PVT compared to those without PVT.

Sharma et al., (2016) reported that low levels of AT III and proteins $\mathrm{C}$ and $\mathrm{S}$ have been reported in cirrhotic; but, it is not certain if this is true inherited thrombophilia or acquired from liver disease in contrast to these result a meta-analysis by Qi et al., (2013) showed that ATIII and proteins $\mathrm{C}$ and $\mathrm{S}$ levels are not significantly related to the development of PVT in cirrhosis. All these findings suggest a new way of dealing with PVT cases complicating liver cirrhosis and HCC at both therapeutic and diagnostic levels.

In this study, cases with positive JAK2 rs V617F mutation were significantly accompanying cases with 
Table 6. Comparison between Negative and Positive JAK2 RS V617F Mutation Cases as Regards Routine Laboratory Data

\begin{tabular}{|c|c|c|c|c|}
\hline Parameter & Data & $J A K 2$ Wild $(\mathrm{N}=72)$ & JAK2Mutant $(\mathrm{N}=28)$ & P-Value \\
\hline \multirow[t]{2}{*}{$\mathrm{HB}(\mathrm{g} / \mathrm{dl})$} & Median (IQR) & $10.0(3)$ & $11.0(2)$ & $0.26(\mathrm{U})$ \\
\hline & Min-max & $7-16$ & $7-14$ & \\
\hline \multirow[t]{2}{*}{ WBCs $\left(\times 10^{3}\right)$} & Median (IQR) & $9.0(5)$ & $9.0(4)$ & $0.45(\mathrm{U})$ \\
\hline & Min-max & $3-19$ & $3-14$ & \\
\hline \multirow[t]{2}{*}{ Platelets $\left(\mathrm{x} 10^{3}\right)$} & Median (IQR) & $132.5(174)$ & $132.5(117)$ & $0.20(\mathrm{U})$ \\
\hline & Min-max & $50-519$ & $57-511$ & \\
\hline \multirow[t]{2}{*}{ Neutrophils \%: } & Median (IQR) & $75.5(16)$ & $81.5(15)$ & $0.06(\mathrm{U})$ \\
\hline & Min-max & $44-91$ & $59-88$ & \\
\hline \multirow[t]{2}{*}{ Lymphocytes \% } & Median (IQR) & $14.5(14)$ & $10.5(9)$ & $0.07(\mathrm{U})$ \\
\hline & Min-max & $4-38$ & $4-30$ & \\
\hline \multirow[t]{2}{*}{$\operatorname{ALT}(\mathrm{IU} / \mathrm{L})$} & Median (IQR) & $31.5(42)$ & $37.5(29)$ & $0.51(\mathrm{U})$ \\
\hline & Min-max & $6-735$ & $16-270$ & \\
\hline \multirow[t]{2}{*}{ AST (IU/L) } & Median (IQR) & $48.5(82)$ & $54.0(54)$ & $0.41(\mathrm{U})$ \\
\hline & Min-max & $8-2248$ & $23-360$ & \\
\hline \multirow[t]{2}{*}{ GGT (IU/L) } & Median (IQR) & $67.0(120)$ & $53.5(99)$ & $0.81(\mathrm{U})$ \\
\hline & Min-max & $12-534$ & $21-456$ & \\
\hline \multirow[t]{2}{*}{ ALK ph (IU/L) } & Median (IQR) & $123.5(8)$ & $140.5(78)$ & $0.66(\mathrm{U})$ \\
\hline & Min-max & $44-990$ & $61-537$ & \\
\hline \multirow[t]{2}{*}{ Albumin (g/dl) } & Median (IQR) & $2.7(1.5)$ & $2.05(1)$ & $0.01(\mathrm{U})$ \\
\hline & Min-max & $1.00-4.9$ & $1.6-3.8$ & \\
\hline \multirow[t]{2}{*}{ T.Bilirubin (mg/dl) } & Median (IQR) & $1.5(6.4)$ & $3.4(7.2)$ & 0.24 \\
\hline & Min-max & $0.3-25.2$ & $0.6-24.6$ & \\
\hline \multirow[t]{2}{*}{ INR } & Median (IQR) & $1.4(0.5)$ & $1.6(0.7)$ & $0.04(\mathrm{U})$ \\
\hline & Min-max & $1.0-2.3$ & $1.1-2.3$ & \\
\hline \multirow[t]{2}{*}{ Urea (mg/dl) } & Median (IQR) & $53.5(108.8)$ & $79.0(112)$ & $0.53(\mathrm{U})$ \\
\hline & Min-max & $20.0-214$ & $24.0-180$ & \\
\hline \multirow[t]{2}{*}{ Creatinine (mg/dl) } & Median (IQR) & $1.1(0.6)$ & $1.1(1.06)$ & $0.90(\mathrm{U})$ \\
\hline & Min-max & $0.6-4.6$ & $0.6-3.4$ & \\
\hline \multirow[t]{2}{*}{ AFP (ng/ml) } & Median (IQR) & $65.825(8175.5)$ & $152.6(1380.9))$ & $0.81(\mathrm{U})$ \\
\hline & Min-max & $73-100,000$ & $1.2-150,218$ & \\
\hline
\end{tabular}

$\mathrm{P}>0.05$ is non-significant; $\mathrm{p}<0.05$ : is significant; Kruskal Wallis (U) test is used

a lessened level of protein $\mathrm{S}$, and a high frequency of ascites. These results are in accordance with literature as PVT was said to be associating the advanced liver disease with severe ascites and liver cirrhosis with the documented reduced levels of protein $\mathrm{S}$. While, the MTHFR heterozygous mutation, ATIII deficiency, and VFL were more frequent with negative $J A K 2$ rs $V 617 F$ mutation and no significant differences were reported regarding the other thrombophilia risk factors, demographic and clinical data with $J A K 2$ mutation in patients with PVT. Therefore, a case of latent MPNs might be present irrespective of the normal thrombophilic factors or coagulation risk factors in hepatic patients, these results agreed with Dentali et al., (2009) who found that MPNs, specifically a JAK2 rs $V 617 F$ mutation, are strongly associated with splanchnic vein thrombosis.

To our knowledge this is one of the first -if not the first- studies who investigated the relationship between JAK2 mutation and PVT complicating liver cirrhosis and or HCC. The great number of PVT cases included in this cross-sectional study is also considered one of the strengths as most related studies relied on a smaller number of cases. However, more similar large-scale studies are mandated with further follow-up for the possibility of detection of MPNs development.

Conclusively, the diagnostic and therapeutic policies of dealing with PVT cases complicating liver cirrhosis had to change with the presumed role of thrombophilic disorders. Also, JAK2 rs $V 617 F$ mutation testing essentially should be added to the list of PVT thrombophilic risk factors and should be investigated in every single case of idiopathic portal vein thrombophilia.

\section{References}

Amitrano L, Brancaccio V, Guardascione MA, et al (2000). Inherited coagulation disorders in cirrhotic patients with portal vein thrombosis. Hepatol Baltim Md, 31, 345-8.

Amitrano L, Guardascione MA, Brancaccio V, et al (2004). Risk factors and clinical presentation of portal vein thrombosis in 
patients with liver cirrhosis. $J$ Hepatol, 40, 736-41.

Basit SA, Stone CD, Gish R (2015). Portal vein thrombosis. Clin Liver Dis, 19, 199-221.

Chawla YK, Bodh V (2015). Portal vein thrombosis. J Clin Exp Hepatol, 5, 22-40.

Colaizzo D, Amitrano L, Tiscia GL (2007). The JAK2 RS V617F mutation frequently occurs in patients with portal and mesenteric venous thrombosis. J Thromb Haemost, 5, 55-61.

Dentali F, Squizzato A, Brivio L, et al (2009). JAK2 RS V617F mutation for the early diagnosis of $\mathrm{Ph}$ - myeloproliferative neoplasmsn in patients with venous thromboembolism: a meta-analysis. Blood, 113, 5617-23.

Fimognari FL, Violi F (2008). Portal vein thrombosis in liver cirrhosis. Intern Emerg Med, 3, 213-8.

Intagliata NM, Argo CK, Stine JG (2018). Concepts and controversies in haemostasis and thrombosis associated with liver disease: Proceedings of the 7th International Coagulation in Liver Disease Conference. Thromb Haemost, 118, 1491-1506.

Ipsogen (2016): JAK2 MutaScreen Kit Handbook.

Karaköse S, Oruç N, Zengin M (2015). Diagnostic value of the JAK2 RS V617F mutation for latent chronic myeloproliferative disorders in patients with budd-chiari syndrome and/or portal vein thrombosis. Turk J Gastroenterol, 26, 42-8.

Margini C, Berzigotti A (2017). Portal vein thrombosis: the role of imaging in the clinical setting. Dig Liver Dis, 49, 113-20.

Ogren M, Bergqvist D, Björck M, et al (2006). Portal vein thrombosis: Prevalence, patient characteristics and lifetime risk: A population study based on 23,796 consecutive autopsies. World J Gastroenterol, 12, 2115-9.

Palumbo GA, Stella S, Pennisi MS, et al (2019). The role of new technologies in myeloproliferative neoplasms front. Oncol, 26 April https://doi.org/10.3389/fonc.2019.00321.

Pan D, Callahan R (2016). Portal and Mesenteric Vein Thrombosis in a Patient with JAK2 RS V617F Mutation. Proceedings of UCLA Healthcare, volume 2.

Ponziani FR, Zocco MA, Garcovich M (2012). What we should know about portal vein thrombosis in cirrhotic patients: A changing perspective. World J Gastroenterol, 18, 5014-20.

Qi X, Chen H, Han G (2013). Effect of antithrombin, protein C and protein $\mathrm{S}$ on portal vein thrombosis in liver cirrhosis: a metaanalysis. Am J Med Sci, 346, 38-44.

Qiagen (2016): QIAamp ${ }^{\circledR}$ DNA Mini and Blood Mini Handbook.

Rao RBS, Grosel J (2018). Acute portal vein thrombosis in a 59-year-old male with JAK2 RS V617F mutation. Radiol Case Rep, 13, 1249-55.

Sharma AM, Zhu D, Henry Z (2016). Portal vein thrombosis: When to treat and how?. Vascul Med, 21, 61-9.

Tefferi A, Gilliland DG (2005). JAK2 in myeloproliferative disorders is not just another kinase. Cell Cycle, 4, 1053-6.

Tsochatzis EA, Senzolo M, Germani G, et al (2010). Systematic review: portal vein thrombosis in cirrhosis. Aliment Pharmacol Ther, 31, 366-74.

Yonal I, Pinarbas1 B, Hindilerden F (2012). The clinical significance of JAK2 RS V617F mutation for Philadelphianegative chronic myeloproliferative neoplasms in patients with splanchnic vein thrombosis. $J$ Thrombosis Thrombolysis, 34, 388-96.

\section{cc) (i) (8)}

This work is licensed under a Creative Commons AttributionNon Commercial 4.0 International License. 